\title{
Homing abilities of dolphinfish (Coryphaena hippurus) displaced from fish aggregating devices (FADs) determined using ultrasonic telemetry
}

\author{
Charlotte Girard ${ }^{1 \mathrm{a}}$, Laurent Dagorn ${ }^{1}$, Marc Taquet $^{2}$, Riaz Aumeeruddy $^{3}$, Christophe Peignon $^{4}$ \\ and Simon Benhamou ${ }^{5}$ \\ ${ }^{1}$ IRD, UR Thetis, CRH, BP 171, 34230 Sète Cedex, France \\ 2 IFREMER, CRH, BP 171, 34230 Sète Cedex, France \\ 3 SFA, PO Box 449, Victoria, Seychelles \\ 4 IRD, UR Thetis, PO Box 570, Victoria, Seychelles \\ 5 CEFE CNRS, 34293 Montpellier Cedex 5, France
}

Received 5 April 2007; Accepted 2 July 2007

\begin{abstract}
We conducted displacement experiments using acoustic tags to study the orientation abilities of dolphinfish (Coryphaena hippurus) around FADs. Eleven fish were passively monitored using coded transmitters and acoustic receivers attached to FADs, while seven others were actively tracked with a vessel using continuous acoustic tags equipped with pressure sensors. All these 18 dolphinfish were captured close to a FAD and released between 70 and $1720 \mathrm{~m}$ from it. Five fish out of the 14 that were displaced at more than $360 \mathrm{~m}$ from a FAD (estimated detection range of our acoustic receivers, defining the target area during our experiment) returned to the target area. With one individual successfully returning to the target area after having been released at $1600 \mathrm{~m}$ from the FAD, the rate of return of fish released up to this distance was significantly higher than expected if they were moving at random, but many fish released at intermediate distances moved in other directions. Based on detailed statistical analysis of the return score, we estimated that dolphinfish are able to orientate towards a FAD area from at least $820 \mathrm{~m}$. The connection between our definition of the target area and the association area of dolphinfish around a FAD is discussed, as well as the impact of stress and motivation in the rates of return observed. More experiments should be conducted to improve this first estimate. Specific experiments should also be designed to more accurately determine the association range of fish around FADs and their motivation to orientate towards FADs.
\end{abstract}

Key words: Ultrasonic telemetry / Fish behaviour / Horizontal movements / Floating objects / Orientation behaviour / Indian Ocean

Résumé - Étude par télémétrie ultrasonique des capacités de retour de dorades coryphènes (Coryphaena hippurus) déplacées de dispositifs de concentrations de poissons (DCP). Afin d'étudier les capacités de retour vers des dispositifs de concentration de poissons (DCP) des dorades coryphènes (Coryphaena hippurus), nous avons réalisé des expériences de déplacements en utilisant des techniques de télémétrie acoustique. Ainsi, 11 poissons marqués ont été suivis passivement au moyen de récepteurs acoustiques fixés à des DCP, alors que sept autres ont été suivis activement par bateau, en utilisant des marques acoustiques équipées de capteurs de pression. Tous les poissons ont été capturés à proximité d'un DCP et relâchés à des distances comprises entre 70 et $1720 \mathrm{~m}$. Parmi les 14 individus déplacés à plus de $360 \mathrm{~m} \mathrm{du}$ DCP (distance de détection estimée des récepteurs acoustiques, permettant de définir la cible de retour durant notre étude), cinq sont revenus. Le poisson déplacé à 1600 m étant revenu au DCP, le taux de retour des individus relâchés jusqu'à cette distance apparaît significativement plus grand que ce que prévoit l'hypothèse nulle de retour au hasard. Toutefois, plusieurs poissons relâchés à des distances intermédiaires se sont déplacés dans d'autres directions. En nous basant sur une analyse statistique détaillée des taux de retour, nous estimons que les dorades coryphènes sont capables de s'orienter vers un DCP à une distance d'au moins $820 \mathrm{~m}$. Le rapport entre la zone-cible définie pour mesurer les taux de retour des poissons, et la zone d'association des dorades coryphènes autour des DCP est discutée, ainsi que l'impact du

\footnotetext{
a Corresponding author: charlotte.girard@cls.fr Current address: CLS - Division Océanographie Spatiale, 8-10 rue Hermès, 31520 Ramonville St. Agne, France.
} 
stress et de la motivation des poissons sur les taux de retour observés. Davantage d'expériences seraient nécessaires pour améliorer cette première estimation, afin de mieux estimer la distance d'association des poissons aux DCP. Des expériences, visant à étudier la motivation des coryphènes à s'orienter vers ces structures, devraient également être conçues.

\section{Introduction}

Many tropical pelagic fish species such as tunas (yellowfin Thunnus albacares, bigeye Thunnus obesus, skipjack Katsuwonus pelamis), dolphinfish (Coryphaena hippurus) and wahoo (Acanthocybium solandri) are known to associate with objects floating at the surface of the ocean (Castro et al. 2002). These objects can be natural (logs, macro algae, etc.) or derived from human activities (rubbish, fishing buoys, etc.). In all tropical oceans, artificial structures called Fish Aggregating Devices (FADs) have been deployed by fishermen, with the purpose of attracting and concentrating pelagic fish to catch them (Fonteneau et al. 2000). FADs are usually made of surface structures that can be composed of a few buoys or a bamboo raft, and of some underwater structures composed of nets, strap bands or branches. In coastal areas, they are usually moored with a chain or a rope and exploited by artisanal fisheries. Dolphinfish is one of the main target species of these artisanal fisheries worldwide: with the exception of some areas (e.g. French Polynesia), dolphinfish are only captured around FADs (Taquet 2004). On the other hand, industrial fisheries (purse seiners) use drifting FADs to target only tunas, and more than $50 \%$ of the world catch of tropical tunas come from fish associated to FADs. Other species, however, are also caught when purse seiners set around FADs, and dolphinfish is one major by-catch species (Romanov 2002). Understanding the influence of FADs on the spatial behaviour of pelagic species is therefore of upmost importance for fisheries management. This includes not only a good comprehension of the impact of FADs on the behaviour of associated fish, but also their ability to attract fish from larger distances. As a main target species of artisanal fisheries, a major by-catch species of purse seiners, and an emblematic species in fish aggregations around FADs, studying the behaviour of dolphinfish around FADs is essential.

The reasons why some pelagic species associate with floating objects are unclear. If small fish can hide within surface and underwater structures, large pelagic fish such as dolphinfish and tuna certainly cannot. Although a few hypotheses have been proposed (e.g. concentration of food supply, spatial reference, meeting point; see Fréon and Dagorn 2000; Castro et al. 2002 for details), the exact reasons that lead large pelagic fish to associate with floating objects remain unknown. At least, FADs clearly act as particular "places" where fish tend to stay for some time. For instance, Taquet (2004) observed average residence times of dolphinfish around drifting FADs of about 3-4 days. These periods during which dolphinfish were associated to FADs were, however, punctuated with short (tens of minutes to a few hours) excursions further than a few hundreds of meters from the FADs. Long residence times ( $>24 \mathrm{~h}$ ) around anchored FADs have also been reported for other species such as tunas (e.g. Otha and Kakuma 2005; Dagorn et al. 2007). Therefore, FADs can be considered as temporary "homes" for large pelagic fish, in the sense that they represent specific sites where fish tend to stay and return after an excursion.

When associated to a FAD, fish stay within an area that can therefore be considered as a "home range", and which is likely species dependent. Parin and Fedoryako (1999) subdivided the fish community around FADs into "intranatants", which remain within $0.5 \mathrm{~m}$ of the object, "extranatants" $(0.5-2 \mathrm{~m})$ and "circumnatants" ( $2 \mathrm{~m}$ to several kilometres). Fréon and Dagorn (2000) proposed different distance values for these categories, but in both studies these association distances were defined empirically. Castro et al. (2002) proposed to use the term $a g$ gregation for fish closely connected to the floating objects and strongly dependent on their presence (for food, refuge, etc.), and the term association specifically for fish moving around floating objects in a radius of ten to hundreds of meters. Underwater visual census and fishermen empirical knowledge tend to indicate that dolphinfish associate with floating objects: they wander within a large area (several hundred meters) around the structure, and come periodically close to it (a few meters). However, the exact distances from FADs at which dolphinfish usually stay when they are associated to FADs are not known. To our knowledge, only one study investigated the distribution of this species around FADs. Using two types of acoustic tags detectable (during this study) at either 300-400 m or $700 \mathrm{~m}$ from automatic receivers, Taquet (2004) found that dolphinfish associated to drifting FADs spend $75 \%$ of their time within $300-400 \mathrm{~m}$ of the devices. He also showed that dolphinfish periodically perform longer-range excursions (at distances greater than $700 \mathrm{~m}$ ) before coming back to the FAD.

In order to assess the ability of dolphinfish and yellowtail kingfish (Seriola lalandi) to home (i.e. orientate towards a floating object from which they were displaced), Dempster and Kingsford (2003) conducted short-range displacement experiments around moored FADs. A number of fish were equipped with dart tags with colour combinations, displaced at some distances from the FAD, and visually recaptured at the FAD during snorkel dives. Based on their assumption that this species uses vision to locate FADs, and are able to do so within a maximum distance of $20 \mathrm{~m}$, the authors considered that reassociation was successful only when the fish could be seen by the diver (i.e. when it was within $20 \mathrm{~m}$ around the FAD). They concluded that dolphinfish could home from a minimum of $275 \mathrm{~m}$ from FADs, as they did not observe any return of individuals released at $500 \mathrm{~m}$ (maximum release distance tested). Since juvenile and adult dolphinfish, however, are more likely to belong to associated fish than to aggregated ones (dolphinfish being not as strongly connected to FADs as smaller species), a successful re-association might already occur when a fish reaches a larger area around the FAD.

In the present study, our objective was to evaluate the ability of dolphinfish to orient themselves towards a large "target area" centred on a moored FAD, with a radius likely to be of the same order as for the association area for this species (i.e. 
Table 1. Main characteristics of the dolphinfish tracked.

\begin{tabular}{|c|c|c|c|c|c|c|}
\hline Fish ID & $\begin{array}{l}\text { Fork length } \\
(\mathrm{cm})\end{array}$ & $\begin{array}{c}\text { Type of } \\
\text { Tracking }^{\dagger}\end{array}$ & $\begin{array}{l}\text { Distance of } \\
\text { release from } \\
\text { FAD }(\mathbf{m})\end{array}$ & $\begin{array}{l}\text { Return to the } \\
\text { target area } \\
(\mathrm{Y} / \mathrm{N})\end{array}$ & $\begin{array}{c}\text { Individual } \\
\text { probability of } \\
\text { return }(p)\end{array}$ & $\begin{array}{c}\text { Time of } \\
\text { first detection in } \\
\text { the target area } \\
(\mathrm{min})^{\S}\end{array}$ \\
\hline $\mathrm{C} 1$ & 48 & $\mathrm{P}$ & 70 & - & - & 0 \\
\hline $\mathrm{C} 2$ & 60 & $\mathrm{P}$ & 160 & - & - & 4 \\
\hline $\mathrm{C} 3$ & 59 & $\mathrm{P}$ & 250 & - & - & 2 \\
\hline $\mathrm{C} 4$ & 58 & $\mathrm{P}$ & 320 & - & - & 4 \\
\hline C5 & 59 & $\mathrm{P}$ & 400 & $\mathrm{Y}$ & 0.36 & 8 \\
\hline C6 & 63 & $\mathrm{P}$ & 480 & Y & 0.27 & 9 \\
\hline $\mathrm{C} 7$ & 65 & $\mathrm{~A}, \mathrm{P}$ & 820 & $\mathrm{Y}$ & 0.14 & $29(23)$ \\
\hline $\mathrm{C} 8$ & 60 & $\mathrm{P}$ & 860 & $\mathrm{~N}$ & 0.14 & - \\
\hline C9 & 60 & A & 880 & $\mathrm{~N}$ & 0.13 & - \\
\hline $\mathrm{C} 10$ & 60 & $\mathrm{P}$ & 1000 & $\mathrm{~N}$ & 0.12 & - \\
\hline $\mathrm{C} 11$ & 60 & A & 1010 & $\mathrm{~N}$ & 0.12 & - \\
\hline $\mathrm{C} 12$ & 54 & $\mathrm{P}$ & 1030 & Y & 0.11 & 16 \\
\hline $\mathrm{C} 13$ & 67 & A & 1100 & $\mathrm{~N}$ & 0.11 & - \\
\hline $\mathrm{C} 14$ & 85 & $\mathrm{~A}, \mathrm{P}$ & 1130 & $\mathrm{~N}$ & 0.10 & - \\
\hline $\mathrm{C} 15$ & 98 & $\mathrm{P}$ & 1140 & $\mathrm{~N}$ & 0.10 & - \\
\hline C16 & 65 & $\mathrm{P}$ & 1260 & $\mathrm{~N}$ & 0.09 & - \\
\hline $\mathrm{C} 17^{*}$ & 124 & A & 1600 & $\mathrm{Y}$ & 0.07 & 17 \\
\hline $\mathrm{C} 18$ & 69 & $\mathrm{~A}, \mathrm{P}$ & 1720 & $\mathrm{~N}$ & 0.07 & - \\
\hline
\end{tabular}

The black line indicates the threshold between fish released inside vs. outside the target area. ${ }^{\dagger} \mathrm{A}$ and $\mathrm{P}$ mean active and passive tracking, respectively. * Individual displaced from a FAD moored around La Réunion Island. ${ }^{\S}$ Values indicated for fish C17 and in brackets for fish C7 correspond to the time at which the fish entered a 360 m-radius area around the FAD.

a few hundreds of meters). To achieve this, we performed displacement experiments and used acoustic telemetry to monitor the return of the fish within this so-called target area.

\section{Materials and methods}

\subsection{Study site and tagging protocol}

The experiments were conducted in the Seychelles and La Réunion Island (Western Indian Ocean). Seychelles did not have any permanent moored FAD before our experiment. In 2004, we anchored a first FAD around Mahé Island, and in 2005, two other FADs were deployed, separated by a distance of $3 \mathrm{~km}$. These FADs were made of ten buoys on surface, a metal cable, strap bands (at about $20 \mathrm{~m}$ depth) and a concrete block moored at about $60 \mathrm{~m}$ depth. The western coast of La Réunion Island is equipped with about 10 FADs anchored at depths ranging between 500 and $1500 \mathrm{~m}$ (similar structure as for the FADs used in the Seychelles).

Between August 2003 and May 2005, a total of 18 dolphinfish (48-124 cm fork length) were tagged and released at distances ranging from 70 to $1720 \mathrm{~m}$ to the FAD (Table 1). All the dolphinfish were captured using trolling lines within 5 to $100 \mathrm{~m}$ of the FAD. They were placed on a padded cradle and the eyes were covered with a wet chamois in order to avoid any long exposure to light. A plastic hose was inserted in the mouth of the fish to provide a continuous sea water flow and facilitate oxygenation of the gills. Two different types of VEMCO acoustic tags (www.vemco.com) were used to locate the fish after release. Four fish were equipped with continuous acoustic transmitters with pressure sensors (V16P$4 \mathrm{H}, 8 \mathrm{~cm}$-long) attached above their anal fin using a hook, while 11 others were equipped with coded acoustic pingers (V13-1H, 3.7 cm-long; acoustic pulse burst sent with a random delay between 40 and $120 \mathrm{~s}$ ), surgically inserted into the body cavity. For this purpose, a small incision was made in the muscle of the belly wall $1-2 \mathrm{~cm}$ on the side to the centre line of the fish. A pinger was then inserted in the peritoneal cavity and the incision was closed using sutures. Three additional individuals were double tagged (with a V16P-4H and a V13$1 \mathrm{H}$ ), as a way to estimate ranges of detection of coded tags by VR2s (see below). To ensure fast displacement from the FAD to the release site, we used high-speed vessels that could reach 25 knots in a few seconds. Tagging was performed while the vessel was moving to the release point, in order to minimize the time during which the fish was out of the water. The total duration of fish manipulation from capture to release ranged between 1 and $5 \mathrm{~min}$, depending on the release distance. All the experiments were conducted during good weather conditions in calm seas (surface current speed about $0.3 \mathrm{~m} \mathrm{~s}^{-1}$ ). All fish except one (fish C11) were released down the swell, which was also down-current.

\subsection{Active fish tracking}

The fish equipped with a continuous V16P-4H tag were actively tracked from the vessel using a VEMCO VR28 receiving 
system. Hydrophones were deployed on a V-fin depressor towed by the tracking vessel. The onboard receiver connected to a personal computer automatically stored the successive boat locations estimated with a Global Positioning System (GPS), as well as the date, time, depth and bearing of the acoustic signal for each tag detection. Dagorn et al. (2001) reported associations between tagged yellowfin tuna and the tracking vessel during active tracking experiments. While tracking a dolphinfish, we avoided approaching it too closely in order to limit any possible interaction with the tracking vessel, and frequently tested that the fish was not associated with it. Former active tracking of dolphinfish (unpublished data) indicate that the average horizontal speed of these fish is about $1-2 \mathrm{~m} \mathrm{~s}^{-1}$. Theoretically, the return in a straight line of a fish released at the greatest distance from the FAD tested in this study (i.e. $1720 \mathrm{~m}$ ) would take less than $30 \mathrm{~min}$. Considering some possible delay due to various reasons (stress, return path longer than a straight line, etc.), we expected that all fish could be back in the vicinity of the FAD (target area) in less than $90 \mathrm{~min}$. Then, active tracking was stopped after the boat had reached the FAD or 90 min after the fish release, when the fish was a few kilometres away from the FAD.

In addition, the information provided by the pressure sensors linked to the acoustic transmitters enabled us to monitor the vertical behaviour of the individuals actively tracked, and so to have clues on the physiological state of the animal (stress) and on the role of the vertical movements of fish returning to FADs (Westerberg 1982).

\subsection{Passive fish monitoring}

The fish equipped with a coded pinger (V13-1H) were passively tracked using VEMCO VR2 acoustic receivers attached to the two FADs deployed in 2005 in the Seychelles $(5 \mathrm{~m}$ below the surface buoys). When a tagged fish is within the detection range of a VR2, the pulse burst emitted by the pinger is detected by the receiver which decodes its ID and stores it with the date and time of the detection event. The return of displaced individuals could then be automatically monitored without any risk of anthropogenic perturbation. A fish detected by a VR2, however, cannot be precisely located within the detection range (the direction and distance of the acoustic signal cannot be estimated). Also, for various reasons (e.g. interfering noise) a few detection failures (i.e. pulse bursts not decoded) can sometimes occur, even if the coded pinger is close to the receiver.

\subsection{Detection ranges}

The detection ranges of acoustic tags are known to vary depending on the type of tag and the environmental conditions (for instance with temperature and depth of the thermocline, salinity and turbidity; see Pincock and Voegeli 1990). Normally, the most common factor limiting the maximum range is weather-related noise. Beyond that distance, the acoustic signals sent by the transmitters cannot be reliably detected. To estimate the detection range of continuous V16P-4H tags during active tracking, we deployed a tag at two different depths
( 3 and $23 \mathrm{~m}$ ) under a buoy. We then performed several loops around the buoy with the tracking vessel in order to determine the distance at which the tag could not be detected anymore. To estimate the detection range of coded V13-1H tags in our environmental conditions (which defines the radius of our target area; see below), we deployed a tag under a drifting vessel (speed of about $0.4 \mathrm{~m} \mathrm{~s}^{-1}$ ), a few meters below the surface, and recorded the time and distance from a VR2 receiver (attached to the FAD) every minute. Sea conditions were very similar during this test and during all our displacement experiments. To obtain robust estimates, range tests should be done each day of the experiment, which is rarely feasible. Additional estimates however can be provided a posteriori by combining information from the active and passive tracking of double tagged fish which returned to the target area. Relying on (1) the location of the tracking boat at the time of the first detection of the tagged fish by the VR2, (2) the bearing of the acoustic signal detected at the same time by the VR28 receiver, and (3) our estimation of the detection range during active tracking, we estimated a maximum distance between the fish and the VR2 at the time of first detection.

\subsection{Estimating homing abilities}

In this study, the target area for testing the homing abilities of dolphinfish was defined according to our passive observation method: it is the area centred on the FAD with a radius $R$ equal to the detection range of a VR2 in our local conditions. We considered that, after being displaced, a fish returned to this area if it was detected by a VR2 or if, while being actively tracked, it approached the FAD closer than the distance $R$. These fish were described as successful (as opposed to unsuccessful individuals that did not enter the target area within 90 min after release). A successful fish, however, could have reached the target area whether by orientating towards it (i.e. deliberately moving in this preferred direction), or by moving by chance in this direction.

For a fish released at a distance $D>R$, the probability $p$ to return to the FAD by choosing a swimming direction at random is $p=\arcsin (R / D) / \pi$, assuming that the fish moves in straight line after release. The best way to ascertain the distance at which dolphinfish could orientate towards a FAD consists in releasing a number $n$ of fish at each distance of a series of distances. Then, the probability $f(x)$ that exactly $x$ individuals out of $n$ released at a given distance return to the FAD by choosing a swimming direction at random is simply equal to the probability of the particular combination of successful/unsuccessful fish observed, multiplied by the number of combinations with the same score: $f(x)=\left(\begin{array}{l}x \\ n\end{array}\right) p^{x}(1-p)^{n-x}$ (binomial law).

We defined the orientation distance is the distance above which the frequency of fish returning to the FAD is no more than what is expected at random (cumulative distribution function $F(x)<0.95$, corresponding to a unilateral binomial test with a 0.05 type I risk). For large pelagic fish, however, displacement experiments at great distances are difficult to repeat with a high number of individuals. Nevertheless, a first estimation can be proposed with a lower number of individuals by releasing each of them at a different distance from the 


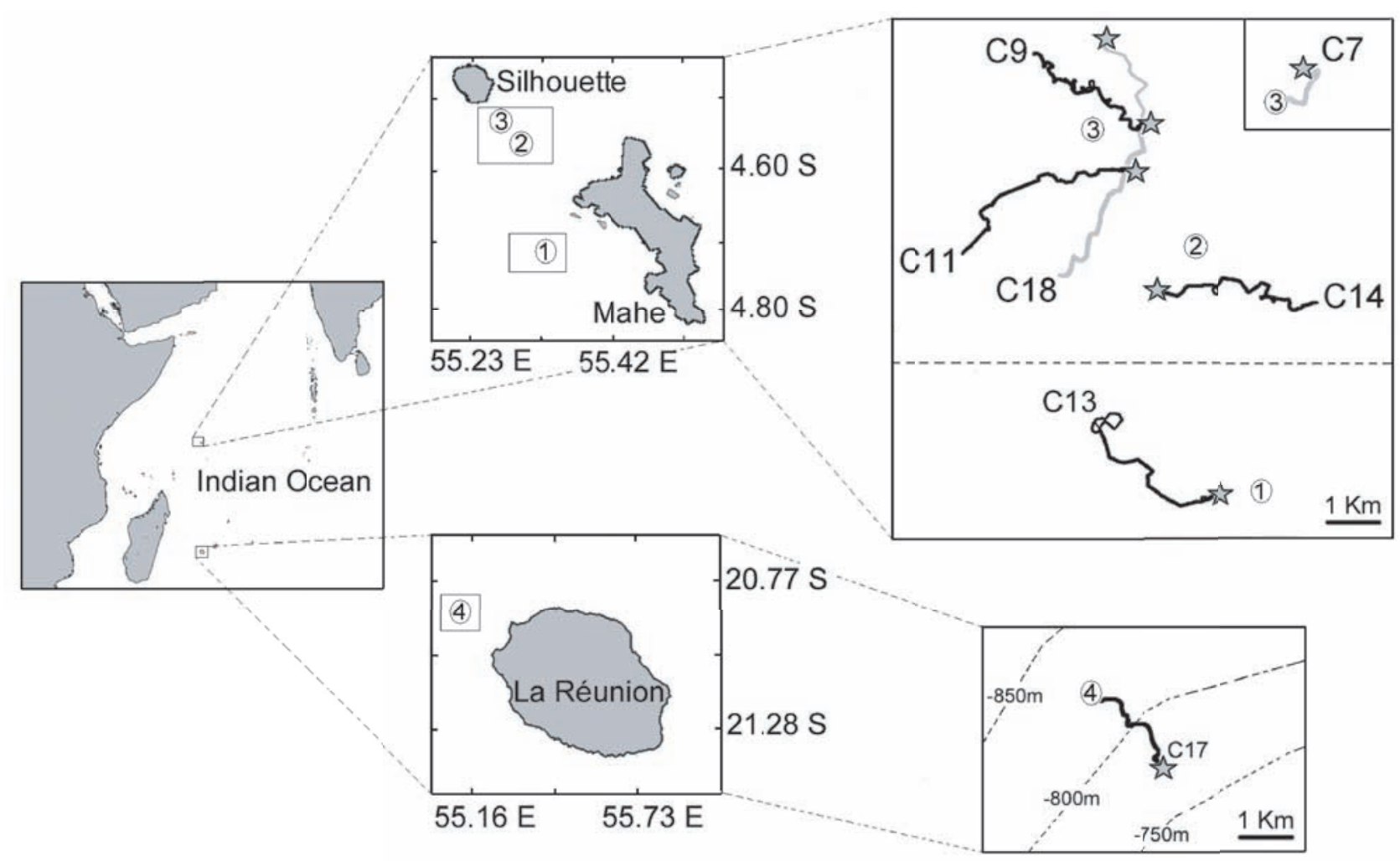

Fig. 1. Horizontal movements of the dolphinfish actively tracked. Numbers in circles stand for the FADs. A star indicates the beginning of each track. Upper part: fish tracked on the Mahé plateau (bottom depth between 50 and $65 \mathrm{~m}$ ); fish C7, C9, C11 and C18 were caught close to FAD 3, fish C13 close to FAD 1 and fish C14 close to FAD 2. Lower part: fish tracked in La Réunion Island, after been caught close to FAD 4 (named "8M Le Port" and anchored $15 \mathrm{~km}$ from the north-western coast, at a depth of approx. $820 \mathrm{~m}$ ). Isobaths are represented by dashed lines. Only the fish $\mathrm{C} 7$ and $\mathrm{C} 17$ returned to the FAD where they were caught.

FAD. In this case, the individual probabilities $p$ for a random return are all different as they depend on the release distances, so that the different combinations of successful/unsuccessful fish that are equivalent in terms of score present different probabilities of occurrence. The probability $f(x)$ of random return of $x$ individuals among $N$ fish released at distances $\leqslant D$ is then obtained by summing the probabilities of occurrence of all the combinations characterized by a return rate equal to $x / N$. The orientation distance can then be estimated based on the cumulative distribution function $F(x)<0.95$ (corresponding in this case to a unilateral Poisson-binomial test with a 0.05 type I risk; see Chen and Liu 1997).

\section{Results}

\subsection{Detection ranges}

Tests during active tracking showed that beyond $200 \mathrm{~m}$, the ratio between the acoustic signal sent by the continuous V16P-4H tag and the ambient noise was too weak to allow any decoding by the VR28 receiving system. The observer could, however, perceive the signal as far as $300 \mathrm{~m}$ by listening to the raw signal.

The first method used to estimate the detection range of a coded V13-1H tag by VR2s revealed that the tag was detected for the last time at a distance of $385 \mathrm{~m}$ from the VR2 (average \pm SEM of the time interval between two detections equal to $126 \pm 35 \mathrm{~s}$ ). During the displacement experiments, only one double tagged individual (fish C7, see below) was detected by the VR2, 29 min after being released. At that time, the tracking vessel was located $205 \mathrm{~m}$ away from the FAD. Considering the bearing of the acoustic signal, we estimated a maximum distance between the fish and the FAD of about $335 \mathrm{~m}$. The radius $R$ or the target area was therefore expected to be comprised between 335 and $385 \mathrm{~m}$. For the following analysis, $R$ was considered to be $360 \mathrm{~m}$ (average detection range).

\subsection{Active and passive tracking}

Among the 18 dolphinfish tagged, four individuals ( $\mathrm{C} 1$, $\mathrm{C} 2, \mathrm{C} 3$ and $\mathrm{C} 4$ ) passively tracked were released between 70 and $320 \mathrm{~m}$ from the FAD, i.e. within the target area (Table 1). They were detected by the VR2 less than four minutes after release. Considering these distances of release, the emission rate of our V13-1H and the possibility of detection failures, we considered as a precaution that these fish were released within the detection range of the VR2 (i.e. within our target area). Therefore, these four fish were discarded from the statistical analyses of return success.

Five out the 14 remaining dolphinfish returned to the target area (Table 1): one was actively tracked (fish $\mathrm{C} 17$ ), three were passively tracked (fish C5, C6 and C12) and one (fish C7) 
was both actively and passively tracked. Detection times by the VR2 (or times to reach the target area during active tracking) ranged between 8 and 29 min.

Active tracking provided useful information on the horizontal and vertical behaviour of dolphinfish. All the seven individuals concerned swam in a relatively straight movement (Fig. 1), no matter if they came back to the FAD area (C7 and C17) or not (C9, C11, C13, C14 and C18). Hence, the horizontal path characteristics cannot be used to discriminate between FAD-oriented and non FAD-oriented movements. These observations indicate that the computation of the individual return probabilities $p$ of choosing a swimming direction randomly and moving in straight line is a fairly valid method to evaluate the dolphinfish orientation abilities.

In contrast, the vertical movements of the dolphinfish look rather heterogeneous (Fig. 2). Fish C17 dived to $144 \mathrm{~m}$ just after release and started to ascend two minutes after. Although in the Seychelles, the dives were limited because of the bottom depth $(50-65 \mathrm{~m})$, four of the six individuals actively tracked first dived after release to $30-40 \mathrm{~m}$ and started to ascend between 4 and $10 \mathrm{~min}$ after. While some fish came periodically close to the surface (C11, C13, C14 and C18) some others (C7, C9 and C17) stayed in deeper waters.

\subsection{Orientation distance}

Considering a target area with a radius $R$ of $360 \mathrm{~m}$, all the individual probabilities of return by choosing a swimming direction at random were high $(p \geqslant 0.07$, see Table 1$)$. In other words, for any single dolphinfish that returned to the target area, the null hypothesis of a swimming direction chosen at random cannot be rejected. To provide some information about the orientation abilities at the population level, however, we have to consider the joint probabilities of return for the various fish along with their status (successful vs. unsuccessful). Among the 13 fish released between 360 and 1600 m, five returned to the target area. The probability to obtain at least this score $(1-F(x))$ is equal to 0.03 . At first sight, this statistically significant result suggests that dolphinfish may be able to orient towards such a target from distances up to $1600 \mathrm{~m}$. However, successful fish were not distributed at random over the range of release distances: the fish released closer to the FAD tended to be more successful than fish released further. Hence, the orientation abilities of dolphinfish might be overestimated by considering together (i) fish able to home (i.e. orientate towards the FAD) and (ii) other fish released further than a critical orientation distance over which they cannot home, but among which some might have returned to the target area only by chance. At shorter distances, the individual probability to reach the target area by moving in a random direction obviously increases, but the high individual probabilities of random return for fish released at short distances from the FAD are not enough to explain the success of three fish released between 400 and $820 \mathrm{~m}$ from the FAD: the probability to obtain such a return rate $(100 \%)$ would be equal to only 0.01 if they had chosen their moving direction at random (while $(1-F(x))=0.1$ if we consider only the two fish released 400 and $480 \mathrm{~m}$ from the FAD). The probability to obtain a least 4 individuals back to the target area among the 8 individuals released up to $1030 \mathrm{~m}$ is also small $(1-F(x)=0.03)$ but, as the 4 individuals released between 860 and $1010 \mathrm{~m}$ were not successful, one might suspect that the fish released $1030 \mathrm{~m}$ from the FAD did it only by chance.

Furthermore, we checked that our results are not too sensitive to the estimated radius of the target area by considering a radius $10 \%$ greater or lower. As the results obtained lead to very similar conclusions to those obtained with a radius $R=360 \mathrm{~m}$, we conclude that our estimate of the minimum orientation distance can be considered as being fairly robust.

\section{Discussion}

As a whole, our results suggest that dolphinfish are able to orientate towards an anchored FAD from at least $820 \mathrm{~m}$. A few fish were also successful from greater distances but since some individuals released at intermediate distances were not, we prefer to adopt a precautionary approach. This minimum orientation distance $(820 \mathrm{~m})$ should therefore be considered only as a first estimate. Using path analysis on active tracking data of yellowfin tuna, Girard et al. (2004) found that this species was able to orientate towards FADs from at least $7 \mathrm{~km}$. Additional displacement experiments should be performed to conclude on the abilities of dolphinfish to orientate towards a FAD from distances greater than $820 \mathrm{~m}$. Several other points also need to be discussed.

\subsection{The target area}

In this study, we estimated the ability of dolphinfish to home to a target area centred on a FAD, with a radius $R$ directly defined by our passive observation method. Statistical analyses were performed assuming that the detection range of V13-1H tags by a VR2 acoustic receiver was constant $(R=360 \mathrm{~m})$. We know, however, that it might change depending on various factors (environmental conditions, depth of the tag, amount of tags used simultaneously, etc.). Therefore, how reliable is our estimation? Apart from the fact that all the experiments using VR2s were performed in the same environmental conditions (which suggests that the detection range might not vary a lot between the days of experiments), the time delay between the release and the first detection may also provide useful information. All the fish released at distances shorter than $360 \mathrm{~m}$ were first detected within $4 \mathrm{~min}$, while the two fish released at the first distances greater than $R$ (i.e. C5 at $400 \mathrm{~m}$ and C6 at $480 \mathrm{~m}$ ) were first detected after 8 and $9 \mathrm{~min}$, respectively. No other tagged fish were in the water at that time (which eliminates the possibility of collisions between acoustic signals, resulting in the absence of detection by the VR2s), and afterwards, fish C5 and C6 were continuously detected for at least $53 \mathrm{~min}$. Given the time delay between detection events observed during our range test $(126 \pm 35 \mathrm{~s})$, we can assume that they were actually released further than the detection range of the VR2, i.e. outside our target area. In addition, the robustness of our estimate of the minimum orientation distance (if we consider a $10 \%$ variation of the radius of the target area) suggests that a slight variation in the detection range of the VR2s would not have been critical for the outcomes of this study. 
a)

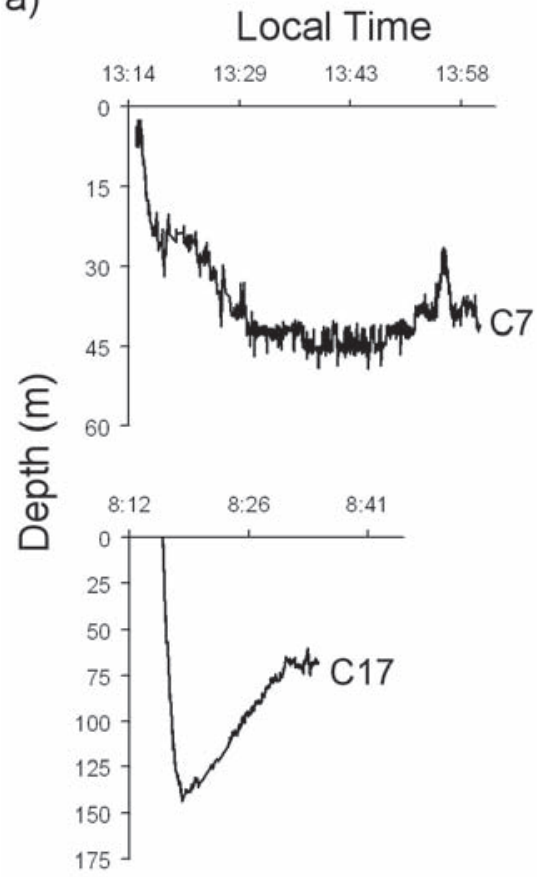

Fig. 2. Vertical movements of the actively tracked dolphinfish. a) Successful fish. b) Unsuccessful fish. Dashed lines correspond to short periods of time where information on the swimming depth of the fish were not available. For all fish except C17 (released in La Réunion Island), the swimming depth was limited by the bottom depth (between 50 and $65 \mathrm{~m}$ ). Note that the $y$-axis scale differs for fish $\mathrm{C} 17$. b)

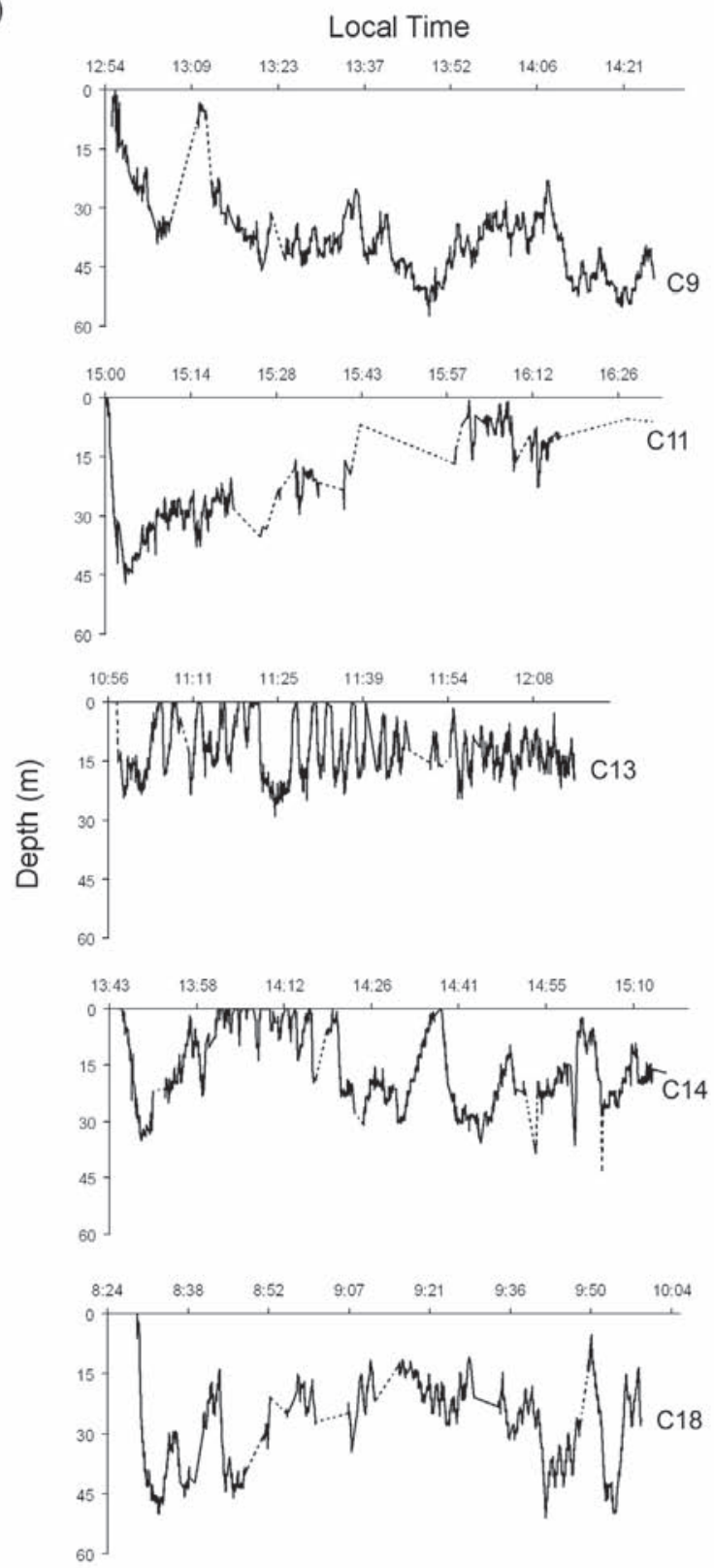

with coded pingers of different power strengths (one with a short detection range and another with a greater one). It would help to better understand the spatial distribution of dolphinfish around FADs.

Our results appear quite different from the orientation distances observed by Dempster and Kingsford (2003). During their study, they displaced dolphinfish $(35-65 \mathrm{~cm})$ at distances equal to 20,75, 275 and $500 \mathrm{~m}$ from the FAD, and they did not observe any return from $500 \mathrm{~m}$ (among the five fish released down-current). The main difference between their study and ours is however a matter of spatial scale: they looked at fish that returned precisely to the FAD (within $20 \mathrm{~m}$ around it) after being probably released in the association area, whereas we aimed to test the ability of dolphinfish to home to a larger area (supposed to represent the association area) after been released further away. Moreover, they displaced juvenile fish while we sociation range would be to deploy listening stations under the FADs, in order to detect the presence of fish double-tagged 
mainly tagged adult dolphinfish, although it has to be proven that juvenile and adult dolphinfish have different orientation abilities.

\subsection{Impact of tagging on the behaviour of dolphinfish}

Assessing the tagging effects on the biology and behaviour of pelagic fish is always difficult, but some indications might be provided by the vertical behaviour of the tagged animals. Dolphinfish C17 dived deeply during the 2 min after release and then slowly went up to $70 \mathrm{~m}$. This behaviour was also observed in other tracking experiments (Taquet 2004; Withney et al. unpublished data). Although fish actively tracked in the Seychelles showed rather heterogeneous vertical behaviours, most of them also dived after release, and they started to ascend between 4 and 10 min afterwards. If the deep dives following the releases are indicators of the stress induced by the experimental treatment, the following ascents could indicate that our dolphinfish recovered within a few minutes after release. Even if the stress impacted the behaviour of the tagged fish for a longer period, what might be the effect of such a trauma on the homing behaviour of dolphinfish? Stress is unlikely to improve sensory abilities of tagged animals. At the worst, it might have a negative impact on the rate of return by reducing the motivation of fish to home. Therefore, stress induced in our experiment might have led to an under-estimation of the orientation abilities of dolphinfish, but not to an overestimation.

\subsection{Motivation of dolphinfish to home}

A key parameter in displacement experiments is indeed the attractiveness of the "home". Usually, the role of this site is clearly identified (e.g. the loft for a homing pigeon). However, the reasons why some pelagic species associate with floating objects are unclear (see Fréon and Dagorn 2000; Castro et al. 2002). Fish associated with a FAD for a long time (e.g. a few days) might be very motivated to return to its vicinity after an experimental displacement. The contrary, however, is not necessarily true: some fish associated with a FAD for a short period of time might also be motivated to return to it after an experimental displacement. In this context, estimating the motivation of pelagic fish to (re)associate to a FAD after being displaced is very difficult. Because of the availability of topographic features, one might hypothesize that dolphinfish are less strongly associated with FADs moored in relatively shallow waters (like on the Seychelles plateau) than in deep waters (like around La Réunion Island). In this case, some fish displaced in the Seychelles might not be as strongly motivated to return to the FAD as expected. This would have led to a lower rate of return, and again, to an under-estimation of the orientation abilities of dolphinfish.

\subsection{Sensory cues}

Sensory cues used by fish to locate FADs are still unknown. Fish might detect chemical or physical (e.g. sounds) cues produced by the marine life associated to the FADs. Some species, such as yellowfin tuna (Atema et al. 1980) and sharks (Carrier et al. 2004), are sensitive to very low concentrations of chemical compounds and can use odours for detection and orientation to specific areas (Atema et al. 2002). This hypothesis was tested by Dempster and Kingsford (2003), but due to some failings in their protocol (in particular, the delay between the release of fish and their visual recapture), we believe that more studies are necessary before concluding on the role of chemical cues in orientation to FADs. Our study was not designed to test this hypothesis, with all the fish except one released down-current. It is noteworthy, however, that in the Seychelles, the FADs were deployed a few weeks before the experiments and were not colonised by a lot of sessile organisms. Moreover, we never observed any large aggregation of fish around our FADs: visual observations when snorkelling at the FADs showed an average number of 5 to 10 dolphinfish per FAD, with an average number of 15 to 20 small rainbow runner (Elagatis bipinnulata) and very few juveniles of other species (e.g. Kyphosus sp., Platax teira) aggregated very close to the device. It is therefore likely that odour cues around our FADs were much weaker than around drifting FADs found in the open ocean, to which hundreds and even thousands of individuals of different species might be associated (Taquet 2004). As suggested by Fréon et al. (2000) and Dempster and Kingsford (2003), dolphinfish may also use sounds produced by the FAD itself or by the fish associated with it. Again, as we encountered very small aggregations, it is very unlikely that they produced strong acoustic signals that the dolphinfish could use to locate the FAD after displacement. Anchored FADs and their mooring line however certainly produce sounds. Particular experiments are needed to further investigate whether or not dolphinfish can detect these sounds, and if so from what distance(s).

In some cases, the analysis of the vertical movements of fish is likely to provide new insight in the study of their orientation behaviour. For instance, several attempts have been made to connect the vertical behaviour of fish with the search of chemical cues (e.g. Barbin 1998; Døving and Stabell 2003). The vertical movements of the dolphinfish actively tracked were rather heterogeneous. However, it seems that fish which returned to the target area $(\mathrm{C} 7$ and $\mathrm{C} 17)$ exhibited vertical movements with lower amplitude than the other fish (C9, C11, $\mathrm{C} 13$ and $\mathrm{C} 14)$. Although the number of individuals tracked in our study is not high enough to conclude, this observation tends to show a relation between the vertical movements of dolphinfish and their orientation abilities. Dolphinfish might adapt their swimming depths to look for orientation cues.

\section{Conclusion}

Since thousands of drifting FADs are regularly deployed by fishermen in the oceans, there is an urgent need to assess the effects of these FADs on the behaviour of pelagic fish. Determining how fish can detect FADs and how they can orientate towards them is of particular importance for future models aiming at studying the impacts of FADs on pelagic fish. This study indicates that dolphinfish can orientate towards FADs from at least $820 \mathrm{~m}$. Further experiments are needed to 
conclude on the ability of dolphinfish to home from further away. A better understanding of the fine-scale behaviour of fish around FADs, and of their motivation to associate with FADs, is critical to design new studies on the orientation behaviour of pelagic fish around FADs.

Acknowledgements. We would like to thank the volunteers who helped with fishing and tagging and the crews of the three vessels (the "Quizás", "Scarab" and "Horny") used to tag and track the dolphinfish. Experiments were conducted during the Fish Aggregating Devices as Instrumented Observatories of pelagic ecosystems (FADIO) project, funded by the DG Research of the European Commission (contract \# QLRT-CI-2001-02773). C.G. benefited from a PhD grant provided by La Région Réunion.

\section{References}

Atema J., Holland K., Ikehara W., 1980, Olfactory responses of yellowfin tuna (Thunnus albacares) to prey odors: chemical search image. J. Chem. Ecol. 6, 457-465.

Atema J., Kingsford M.J., Gerlach G., 2002, Larval reef fish could use odour for detection, retention and orientation to reefs. Mar. Ecol. Prog. Ser. 241, 151-160.

Barbin G.P., 1998, The role of olfaction in homing and estuarine migratory behaviour of yellow phase American eels. Can. J. Fish. Aquat. Sci. 55, 564-575.

Carrier J.C., Musick J., Heithaus M., 2004, Biology of sharks and their relatives. CRC Press, LLC. Boca Raton.

Castro J.J., Santiago J.A., Santana-Ortega A.T., 2002, A general theory on fish aggregation to floating objects: An alternative to the meeting point hypothesis. Rev. Fish Biol. Fish. 11, 255-277.

Chen S.X., Liu J.N., 1997, Statistical applications of the PoissonBinomial and conditional Bernoulli distributions. Stat. Sinica 7, 875-892.

Dagorn L., Josse E., Bach P., 2000, Individual differences in horizontal movements of yellowfin tuna (Thunnus albacares) in nearshore areas in French Polynesia, determined using ultrasonic telemetry. Aquat. Living Resour. 13, 193-202.

Dagorn L., Josse E., Bach P., 2001, Association of yellowfin tuna (Thunnus albacares) with tracking vessels during ultrasonic telemetry experiments. Fish. Bull. 99, 40-48.

Dagorn L., Holland K.N., Itano D.G., 2007, Behavior of yellowfin (Thunnus albacares) and bigeye (T. obesus) tuna in a network of fish aggregating devices (FADs). Mar. Biol. 151, 595-606.

Dempster T., Kingsford M.J., 2003, Homing of pelagic fish to fish aggregating devices (FADs): an investigation of the role of sensory cues. Mar. Ecol. Prog. Ser. 258, 213-222.
Døving K.B., Stabell O.B., 2003, Trails in open waters: sensory cues in salmon migration. In: Sensory processing in aquatic environments. In: Collin S.P., Marshall N.J. (Eds.), Springer-Verlag, New York, pp. 39-52.

Fonteneau A., Pallares P., Pianet R., 2000, A worldwide review of purse seine fisheries on FADs. In: Le Gall J.-Y., Cayré P., Taquet M. (Eds.), Pêche thonière et dispositifs de concentration de poissons. Ifremer, Actes Colloq. 28, pp. 15-34.

Fréon P., Dagorn L., 2000, Review of fish associative behaviour: toward a generalisation of the meeting point hypothesis. Rev. Fish Biol. Fish. 10, 183-207.

Fréon P., Hall M., Marsac F., 2000, Prospective of methods and experiments on pelagic fishes aggregation by FADs. In: Le Gall J.-Y., Cayré P., Taquet M. (Eds.), Pêche thonière et dispositifs de concentration de poissons. Ifremer, Actes Colloq. 28, pp. 36-54.

Girard C., Benhamou S., Dagorn L., 2004, FAD: Fish Aggregating Device or Fish Attracting Device? A new analysis of yellowfin tuna movements around floating objects. Anim. Behav. 67, 319326.

Ohta I., Kakuma S., 2005, Periodic behavior and residence time of yellowfin and bigeye tuna associated with fish aggregating devices around Okinawa Islands, as identified with automated listening stations. Mar. Biol. 146, 581-594.

Parin N.V., Fedoryako B.I., 1999, Pelagic fish communities around floating objects in the open ocean. In: Scott M.D., Bayliff W.H., Lennert-Cody C.E., Schaefer K.M. (Eds.), Proc. Internat. Workshop on the Ecology and Fisheries for Tunas Associated with Floating Objects, February 11-13, 1992. Inter-American Tropical Tuna Commission Special Report 11, La Jolla, CA, pp. 447-458.

Pincock D.G., Voegeli F.A. 1990, Quick course in underwater telemetry system. Vemco Limited.

Romanov E.V., 2002, Bycatch in the tuna purse-seine fisheries of the western Indian Ocean. Fish. Bull. 100, 90-105.

Roos D., Tessier E., Berthier P., Berthier L., 2000, Fishing in Reunion Island: description and evolution of the fishing techniques with Fish Aggregating Devices (FADs). In: Le Gall J.-Y., Cayré P.,Taquet M. (Eds.), Pêche thonière et dispositifs de concentration de poissons. Ifremer, Actes Colloq. 28, 333-345.

Taquet M., 2004, Le comportement agrégatif de la dorade coryphène (Coryphaena hippurus) autour des objets flottants. Thèse de Doctorat de l'Université de Paris 6, Océanologie biologique, Ifremer, $168 \mathrm{p}$.

Westerberg H., 1982, The orientation of fish and the vertical stratification at fine- and microstructure scales. In: Mc Cleave J.D., Arnold G.P., Dodson J.J., Neill W.H. (Eds.), Mechanisms of Migration in Fishes, New York, Plenum, pp. 179-203. 